\title{
Long-Term Effect of Cholinesterase Inhibitors and Special Nursing Home Replacement on Lifetime Expectancy for Alzheimer Disease and Dementia with Lewy Bodies: The Osaki-Tajiri Project
}

\author{
Kenichi Meguro* \\ Geriatric Behavioral Neurology, Tohoku University CYRIC, Japan
}

Submission: February 08, 2018; Published: May 01, 2018

*Corresponding author: Kenichi Meguro, Geriatric Behavioral Neurology, Tohoku University CYRIC, and the Osaki-Tajiri SKIP Center 4-1, Seiryomachi, Aoba-ku, IDAC, 980-8575 Sendai, Japan; Email: k-meg@umin.ac.jp

\section{Mini Review}

Previous studies noted that cognitive impairment or dementia with advancing age is a negative predictor of survival [1], which was attributed not only to a decreased biological vitality [2] but also to a multifactorial phenomenon with origins that operate across the entire lifespan [3]. According to a recent [4] systematic review, survival after diagnosis of dementia was associated with various factors. Life expectancy decreases with age at diagnosis, gender, dementing diseases, and severity.

Unfortunately no curative drugs for neurodegenerative diseases such as Alzheimer disease (AD) or dementia with Lewy bodies (DLB); however, symptomatic drugs such as cholinesterase inhibitors (ChEIs) or meantime may delay progression of the disease. This comprehensive approach with psychosocial interventions can improve quality of life (QOL) [5]. Beyond delayed progression and increased QOL, the ultimate outcome of drug treatment should be measured in terms of life expectancy. Lopez et al. [6] reported that ChEIs can delay a time to a nursing home replacement without apparent effect on life expectancy, whereas a Swedish mega data analysis [7] noted that ChEIs were related to a lower risk of death.

We therefore retrospectively analyzed the influence of donepezil on life expectancy after onset of $\mathrm{AD}$, together with the effects of special nursing home (SNH) replacement [8], where a comprehensive approach with sophisticated psychosocial interventions [9-13] were available. The data of outpatients at the Tajiri Clinic at the Osaki-SKIP Center from with available medical records and death certificates were analyzed. The entry criteria were a dementia diagnosis based on DSM-IV criteria and the available diagnostic criteria of dementing diseases (AD, vascular dementia (VaD), and DLB, respectively); medical treatment for $>3$ months; and follow up until <1 year before death. Of 390 subjects with medical records and death certificates, 275 had a diagnosis of dementia that met the entry criteria. Of 100 patients diagnosed with AD, 52 had taken donepezil and 48 had not received the drug (due to treatment prior to introduction of donepezil in 1999 in Japan). The lifetime expectancies after onset were 7.9 and 5.3 years in these respective groups.

There was a significant drug effect with a significant covariate effect of nursing home residency. Other covariates did not reach a significant level. We further analyzed the effect of concomitant cerebrovascular disease (CVD) and VaD [14]. Of 390 subjects, 275 had a diagnosis of dementia that met the entry criteria, including 67 with pure AD, 33 with AD and CVD, and 110 with VaD. Of the AD patients, 52 had taken donepezil and 48 had not received the drug, as described above. In the pure AD group, there were positive effects of SNH residence and donepezil on lifetime expectancy. In the AD with CVD group, donepezil only had an effect on life expectancy.

Recently donepezil has been indicated for use in the treatment of dementia with DLB; however, the effect on lifetime expectancy remains unclear. Herein, we analyzed the effects of donepezil on DLB [15]. We identified 510 subjects based upon medical records and death certificates, of which 360 had a diagnosis of dementia that met the entry criteria. Of 51 patients diagnosed with DLB, 23 had taken donepezil and 28 patients had not undergone drug treatment due to treatment prior to the introduction of donepezil in 1999 in Japan. The lifetime expectancies after onset were 6.4 years in the donepezil group and 3.6 years in the non-donepezil group; with a significant drug effect. However, in contrast with the previous AD data, no significant effect of SNH residency was noted.

Although these retrospective reports have the limitation of a lack of randomization, we disclosed a positive effect of donepezil on lifetime expectancy after onset of $\mathrm{AD}$, together with the importance of CVD prevention. This may be due to decreased mortality caused by reduction of concomitant diseases such 
as pneumonia. The similar life expectancies in patients taking donepezil at home and those not taking donepezil in a SNH indicated a positive health economic effect of the drug. For DLB, the lower life expectancy compared with that of AD and the lack of an effect of SNH residency suggest the cholinergic deficiency in DLB is greater than that in AD.

\section{References}

1. Maier H, Smith J (1999) Psychological predictors of mortality in old age. J Gerontol B Psychol Sci Soc Sci 54(1): 44-54.

2. Johnson JK, Lui LY, Yaffe K (2007) Executive function, more than global cognition, predicts functional decline and mortality in elderly women. J Gerontol A Biol Sci Med Sci 62(10): 1134-1141.

3. Backman L, MacDonald SWS (2006) Death and cognition: Synthesis and outlook. Eur Psychol 11(3): 224-235.

4. Brodaty H, Seeher K, Gibson L (2012) Dementia time to death: A systematic literature review on survival time and years of life lost in people with dementia. Int Psychogeriatr 24(7): 1034-1045.

5. Meguro M, Kasai M, Akanuma K, Ishii H, Yamaguchi S, et al. (2008) Comprehensive approach of donepezil and psychosocial intervention on cognitive function and quality of life for Alzheimer's disease: The Osaki-Tajiri Project. Age Ageing 37(4): 469-473.

6. Lopez OL, Becker JT, Wisniewski S, Saxton J, Kaufer DI, et al. (2002) Cholinesterase inhibitor treatment alters the natural history of Alzheimer's disease. J Neurol Neurosurg Psychiatr 72(3): 310-314.

7. Nordström P, Religa D, Wimo A, Winblad B, Eriksdotter M (2013) The use of cholinesterase inhibitors and the risk of myocardial infarction and death: a nationwide cohort study in subjects with Alzheimer's disease. Eur Heart J 34(33): 2585-2591.

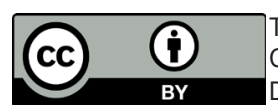

This work is licensed under Creative Commons Attribution 4.0 Licens DOI: 10.19080/OAJNN.2018.07.555717
8. Meguro K, Kasai M, Akanuma K, Meguro M, Ishii H, et al. (2014) Donepezil and life expectancy in Alzheimer's disease: A retrospective analysis in the Tajiri Project. BMC Neurol 14: 83.

9. Meguro M, Meguro K (2010) Activated thalamic glucose metabolism after combined donepezil and psychosocial intervention. British Journal of Neuroscience Nursing 6: 176-180.

10. Meguro K (2017) Cholinesterase inhibitors are compatible with psychosocial intervention for Alzheimer disease patients suggested by neuroimaging findings. Psychiatry Research: Neuroimaging 259: 2933.

11. Meguro M, Ishizaki J, Meguro K (2009) Collage technique may provide new perspectives for Alzheimer patients by exploring messages from their inner world. Dement Neuropsychol 3(4): 299-302.

12. Meguro M, Kasai M, Akanuma K, Ishii H, Yamaguchi S, Meguro K (2008) Comprehensive approach of donepezil and psychosocial interventions on cognitive function and quality of life for Alzheimer's disease: The Osaki-Tajiri Project. Age Ageing 37(4): 469-473.

13. Akanuma K, Meguro K, Meguro M, Sasaki E, Chiba K, et al. (2011) Improved social interaction and increased anterior cingulate metabolism after group reminiscence with reality orientation approach for vascular dementia. Psychiatry Res 192(3): 183-187.

14. Meguro K, Akanuma K, Meguro M, Kasai M, Ishii H, et al. (2015) Lifetime expectancy and quality-adjusted life-year in Alzheimer's disease with and without cerebrovascular disease: Effects of nursing home replacement and donepezil administration - A retrospective analysis in the Tajiri Project. BMC Neurology 15: 227.

15. Meguro K, Kumai K, Takada J, Chida K, Kato Y, et al. (2018) Lifetime expectancy in dementia with lewy bodies: Effects of donepezil administration and special nursing home replacement. a retrospective analysis in the tajiri project. J Alzheimers Dis Parkinson 8(1): 416.

\section{Your next submission with Juniper Publishers will reach you the below assets}

- Quality Editorial service

- Swift Peer Review

- Reprints availability

- E-prints Service

- Manuscript Podcast for convenient understanding

- Global attainment for your research

- Manuscript accessibility in different formats ( Pdf, E-pub, Full Text, Audio)

- Unceasing customer service

Track the below URL for one-step submission https://juniperpublishers.com/online-submission.php 